\title{
Fibroma da bainha do tendão patelar: Um novo paradigma
}

\section{Fibroma of the Patellar Tendon Sheath: A New Paradigm}

\author{
João Boavida1(1) Rui Sousa Grandão ${ }^{2(0)}$ Maria Pia Monjardino ${ }^{10}$ Catarina Quintas ${ }^{10}$ \\ João Pedro Oliveira ${ }^{1}$ (1)
}

1 Serviço de Ortopedia, Centro Hospitalar e Universitário de Coimbra EPE, Coimbra, Portugal

2 Unidade de Saúde Familiar (USF) Briosa, Centro de Saúde Norton de Matos, Coimbra, Portugal

\begin{abstract}
Endereço para correspondência João Boavida, Interno de Formação Específica em Ortopedia, Serviço de Ortopedia, Centro Hospitalar e Universitário de Coimbra EPE, Coimbra, Portugal (e-mail: joaoboavida8@gmail.com).
\end{abstract}

Rev Bras Ortop

\section{Resumo \\ Palavras-chave \\ - fibroma \\ - joelho \\ - tendães \\ - patela}

Os autores apresentam um caso de um fibroma da bainha de tendão com localização intra-articular no joelho e origem na gordura infrapatelar. Esta localização específica é extremamente rara, sendo este o quarto caso descrito de uma entidade que raramente afeta grandes articulações. Para o seu diagnóstico aspetos clínicos, epidemiológicos e sobretudo achados imagiológicos da ressonância magnética são fundamentais. Neste caso o diagnóstico definitvo foi apenas estabelecido após estudo histológico da massa excisada por mini-artrotomia.
The authors present a case of fibroma of the tendon sheath with intra-articular location in the knee, more specifically in the infrapatellar fat; with this specific location, this is the fourth case described of an entity that rarely affects large joints. Clinical and epidemiological aspects, but especially the imaging findings on magnetic resonance imaging scans, are essential for the differential and definitive diagnosis, which was nevertheless established only after a histological study of the excised mass by miniarthrotomy.

\section{Introdução}

O fibroma da bainha de tendão (FBT) é uma lesão tumoral reativa com origem na membrana sinovial da bainha do tendão, benigna e rara, ${ }^{1}$ descrita pela primeira vez por Geschickter e Copeland ${ }^{2}$ em 1949. É definida como uma neoplasia nodular de crescimento lento adjacente à bainha do tendão, clinicamente manifestada por uma pequena massa ou derrame articular que afeta essencialmente pessoas entre os $20 \mathrm{e}$ 50 anos de idade, sobretudo homens, e mais comummente as articulações dos dedos e da mão, sendo relativamente rara nas grandes articulações. ${ }^{3,4}$ Nestas, o joelho é a localização mais comum, contudo, mais comummente associada ao ligamento cruzado e à cápsula posterior, existindo apenas 3 casos descritos na literatura de tumores de bainha do tendão emergentes da bolsa de Hoffa infrapatelar. ${ }^{5}$ Os autores apresentam um caso de um FBT patelar em nível intra-articular.

\section{Relato de Caso}

Um homem de 39 anos, médico de profissão, recorreu à consulta de Ortopedia por dor anterior no joelho esquerdo, recebido

17 de Agosto de 2020

aceito

17 de Setembro de 2020
DOI https://doi.org/

10.1055/s-0040-1722594.

ISSN 0102-3616. (c) 2021. Sociedade Brasileira de Ortopedia e Traumatologia. All rights reserved.

This is an open access article published by Thieme under the terms of the Creative Commons Attribution-NonDerivative-NonCommercial-License, permitting copying and reproduction so long as the original work is given appropriate credit. Contents may not be used for commercial purposes, or adapted, remixed, transformed or built upon. (https://creativecommons.org/ licenses/by-nc-nd/4.0/)

Thieme Revinter Publicações Ltda., Rua do Matoso 170, Rio de Janeiro, RJ, CEP 20270-135, Brazil 


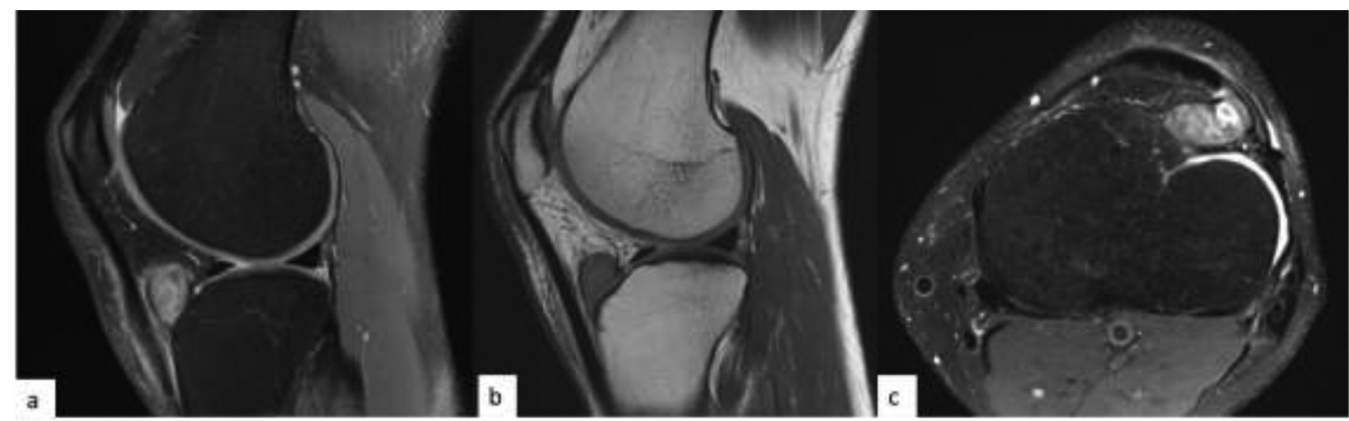

Fig 1. Imagens da relativa isointensidade no plano sagital em T2 (a), T1 (b), e plano axial em T2 (c)

ligeira e presente sobretudo na fase inicial dos sintomas, e massa de tecidos moles associada com cerca de 12 meses de evolução e crescimento lento. 0 paciente negava história de traumatismo prévio ou queixas anteriores nesse joelho. A amplitude articular do joelho estava preservada, com extensão até $0^{\circ}$ e flexão até $130^{\circ}$, com desconforto a partir dos $90^{\circ}$ de flexão. Não havia derrame articular do joelho ou instabilidades aparentes. A massa localizava-se na região anterolateral do joelho, lateral ao tendão patelar, sendo mole, indolor à palpação, de consistência duro-elástica, com cerca de $4 \mathrm{~cm}$ no maior eixo e $2 \mathrm{~cm}$ de largura. Analiticamente, não havia alterações, e, no estudo ecográfico e radiológico do joelho, tampouco se observaram alterações. A ressonância magnética (RM) mostrou uma massa de tecidos anexa à bolsa de Hoffa na região anterolateral do joelho anterior ao prato lateral da tíbia e posterolateral ao tendão patelar, com $3,9 \mathrm{~cm} \times 1,9 \mathrm{~cm}$ de sinal isointenso ao músculo, quer em T1 quer em T2, com focos de hiperintensidade e de bordas bem limitadas (-Figura 1). Levantou-se como hipótese de diagnóstico tratar-se de um tumor de células gigantes (TCG). Optou-se por se realizar uma resseção marginal da lesão por miniartrotomia parapatelar lateral, constatando-se que se tratava de uma lesão intracap- sular e intrassinovial com pedículo à bolsa de Hoffa, lateral à tuberosidade anterior da tíbia e posterolateral ao tendão patelar. $O$ pedículo foi ressecado, e a lesão, totalmente excisada, obtendo-se um fragmento ovalado e irregular com $4 \mathrm{~cm}$ x $2 \mathrm{~cm}$ $\mathrm{x} 1,5 \mathrm{~cm}$, com superfície de secção branca, brilhante e lobulada (-Figura 2). No estudo anatomopatológico, observou-se que a lesão correspondia sobretudo a um estroma fibro-hialino em que as fibras colagênicas estão limitadas por fibroblastos alongados, monótonos e sem atipia, bem como por um componente neovascular, observando-se ocasionalmente superfície revestida por epitélio de tipo sinovial (-Figura 3). Desta forma, foi estabelecido o diagnóstico de FBT patelar do joelho. Com dez meses de evolução, o doente nega dor ou qualquer limitação funcional associada, sem sinais de recorrência local da lesão.

\section{Discussão}

Os FBTs envolvem sobretudo as articulações dos dedos, mão e punho, sendo que $75 \%$ a $82 \%$ deles são encontrados nestas localizações, correspondendo na maioria das vezes a um nódulo pequeno, firme, indolor e de crescimento lento

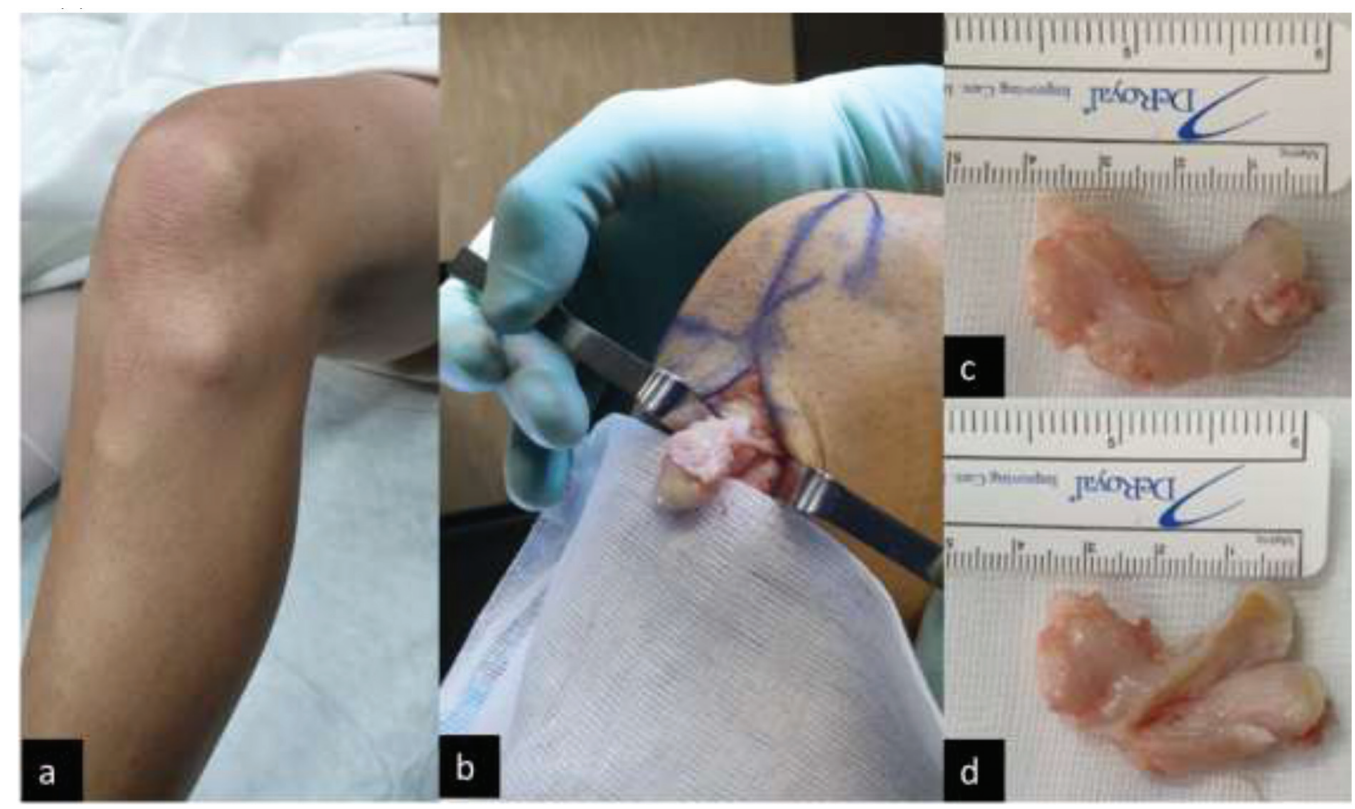

Fig 2. Fotografias intraoperatórias: (a) localização e aspeto clínico; (b) lesão pediculada antes da sua excisão completa; c) aspecto macroscópico e medição do maior eixo, de aproximadamente $4 \mathrm{~cm}$; d) aspecto macroscópico intralesional relativamente homogêneo. 


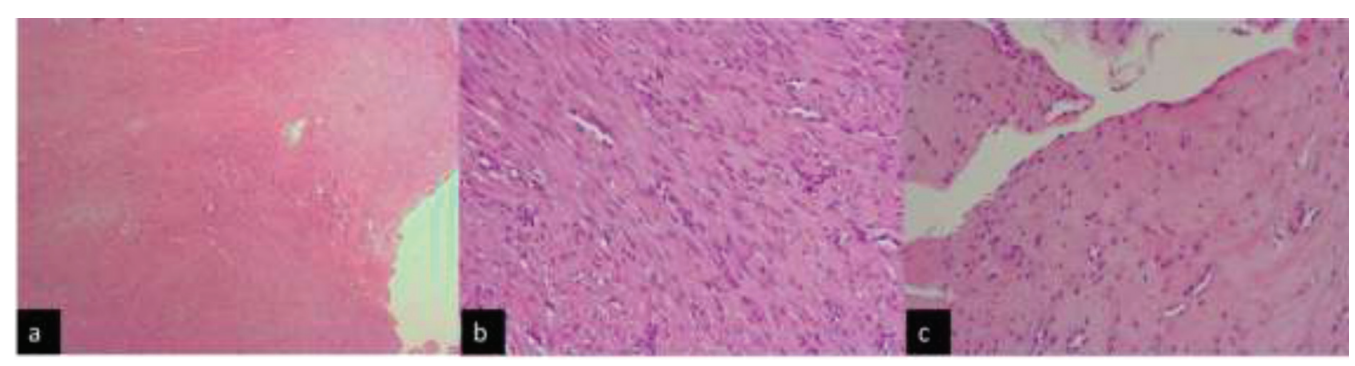

Fig 3. Fotomicrografia: (a) proliferação de estroma fibro-hialino; (b) fibroblastos alongados e monótonos; (c) superfície revestida por epitélio sinovial.

dependente do tendão ou da sua bainha, com um pico de incidência na terceira e quarta décadas de vida e de 3 a 5 vezes mais comum nos homems. ${ }^{6}$ Apesar de o joelho ser a grande articulação mais frequentemente envolvida, foram descritos menos de 40 casos, a maioria com origem no ligamento cruzado posterior ou na cápsula posterior, sendo que, nas grandes articulações, os sintomas mais desritos são dor e massa palpável inferior a $7 \mathrm{~cm}$, por esta ordem de frequência. ${ }^{5} \mathrm{O}$ caso apresentado enquadra-se na maioria das características clínicas e epidemiológicas descritas como mais comuns, excetuando a localização, existindo apenas três casos descritos dependentes do tendão patelar e três dependentes da gordura infrapatelar. $^{5}$

O estudo imagiológico com raio-x ou tomografia axial computarizada neste tipo de lesões é normal, podendo raramente observarem-se alterações ósseas erosivas ou alterações de partes moles em lesões de maiores dimensões. ${ }^{7}$ Os achados da RM do FBT são geralmente constantes em T1, mostrando geralmente uma lesão bem definida de baixo sinal ou isointensa ao músculo; contudo, as imagens em T2 mostram uma grande variabilidade de padrões, mais comumente um sinal de baixa intensidade ao músculo, podendo observar-se também: uma zona central de alta intensidade numa matriz de baixa intensidade, sinal de alta intensidade focal, ou imagem de alta intensidade em toda a massa. ${ }^{5} \mathrm{O}$ caso descrito, ao demonstrar uma lesão isointensa ao músculo em T1 e relativamente isointensa também em T2, com focos de hiperintensidade, levou os autores a considerarem inicialmente como hipótese mais provável tratar-se de um TCG, caraterísticamente isointenso ou de baixa intensidade, quer em T1, quer em T2. ${ }^{8}$ Além do TCG, cuja presença no exame histológico de células gigantes multinucleadas e depósitos de hemossiderina é fundamental para o diagnóstico, o FBT tem como diagnóstico diferencial a fasceíte nodular. ${ }^{5}$ A variabilidade possível em T2 na RM torna o diagnóstico diferencial com a fasceíte nodular incerto; contudo, o fato de raramente apresentar localização intra-articular, de estar associada a uma massa de crescimento rápido e mais comumente dolorosa, e de apresentar tecido mais velho, com estroma mixoide mais proeminente, com extravasamento de células vermelhas e sem qualquer padrão vascular no exame histológico, diferenciam a fasceíte nodular do FBT, no qual um padrão nodular, por vezes, com pequenos canais vasculares tipo fenda e revestido por epitélio sinovial são típicos. ${ }^{4} \mathrm{O}$ tratamento de escolha destas lesões é a excisão marginal, sendo feita na maioria das vezes por via aberta. ${ }^{5}$ Apesar de Chung e Enzinger ${ }^{9}$ terem relatado uma taxa de recorrência de $24 \%$, nas grandes articulações, como o joelho, não existe qualquer caso descrito na literatura. ${ }^{5}$ Convém, contudo, salientar que, dada a ausência de certeza absoluta da remoção completa da lesão no caso descrito, é importante um seguimento cuidadoso para excluir a recorrência.

Em conclusão, este caso reforça a importância de incluir o FBT no diagnóstico diferencial de massas de tecidos moles no nível do joelho.

\section{Consentimento livre e esclarecido}

O termo de consentimento livre e esclarecido foi obtido do paciente para a publicação dos dados referentes ao caso.

\section{Conflito de Interesses}

Os autores declaram não haver conflito de interesses.

\section{Referências}

1 Pinar H, Ozkan M, Ozaksoy D, Pabuççuoğlu U, Akseki D, Karaoğlan O. Intraarticular fibroma of the tendon sheath of the knee. Arthroscopy 1995;11(05):608-611

2 Geschickter CF, Copeland MM. Tumors of bone. 3rd ed. Philadelphia: J.B. Lippincott Co; 1949

3 Aynaci O, Kerimoglu S, Ozturk C, Saracoglu M, Yildiz K. Intraarticular fibroma of the tendon sheath arising from the infrapatellar fat pad in the knee joint. Arch Orthop Trauma Surg 2009;129(03):291-294

4 Griesser MJ, Wakely PE, Mayerson J. Intraarticular fibroma of tendon sheath. Indian J Orthop 2011;45(03):276-279

5 Suzuki K, Yasuda T, Suzawa S, Watanabe K, Kanamori M, Kimura T. Fibroma of tendon sheath around large joints: clinical characteristics and literature review. BMC Musculoskelet Disord 2017;18 (01):376

6 Hitora T, Yamamoto T, Akisue T, et al. Fibroma of tendon sheath originating from the knee joint capsule. Clin Imaging 2002;26 (04):280-283

7 Kundangar R, Pandey V, Acharya KK, Rao PS, Rao L. An intraarticular fibroma of the tendon sheath in the knee joint. Knee Surg Sports Traumatol Arthrosc 2011;19(11):1830-1833

8 Wang CS, Duan Q, Xue YJ, et al. Giant cell tumour of tendon sheath with bone invasion in extremities: analysis of clinical and imaging findings. Radiol Med (Torino) 2015;120(08):745-752

9 Chung EB, Enzinger FM. Fibroma of tendon sheath. Cancer 1979; 44(05):1945-1954 